\title{
Efficient Transmission of Borrelia burgdorferi Between Cofeeding Ixodes ricinus Ticks (Acari: Ixodidae)
}

\author{
LISE GERN AND OLIVIER RAIS
}

Institut de Zoologie, Université de Neuchâtel, Neuchâtel, Switzerland

\begin{abstract}
J. Med. Entomol. 33(1): 189-192 (1996)
ABSTRACT Feeding ticks are generally spatially distributed in clusters on vertebrate hosts. To test the effect of clustering on transmission of a tick-borne pathogen, Borrelia burgdorferi Johnson, Schmid, Hyde, Steigerwalt \& Brenner-infected Ixodes ricinus L. nymphs and uninfected $I$. ricinus larvae were allowed to feed together in retaining chambers on uninfected AKR/N mice. Engorged infective nymphs dropped off at days 5, 6, and 7, and the 1st infected larvae that fed in the chambers together with the infected nymphs dropped off at day 5 . In contrast, ear biopsies and xenodiagnostic larvae placed on the head remained negative during that period. These results suggest that a cofeeding transmission occurred between $B$. burgdorferi-infected ticks and noninfected ones in the absence of a disseminated infection. Further investigations are being undertaken to determine whether the mechanism responsible for this cofeeding transmission is similar to that described previously with virus-infected ticks.
\end{abstract}

KEY WORDS Borrelia burgdorferi, Ixodes ricinus, cofeeding transmission, localized infection, disseminated infection

Borrelia burgdorferi Johnson, Schmid, Hyde, Steigerwalt \& Brenner, the agent of Lyme borreliosis, is a motile extracellular bacterial organism transmitted to the host by the bites of infected ticks belonging mostly to the Ixodes ricinus $\mathrm{L}$. complex. When an infected tick feeds on an animal host, $B$. burgdorferi spirochetes, present in the tick midgut, migrate through the midgut wall a few hours after the onset of the blood meal, reach the hemolymph, and invade various tick organs, including salivary glands, from which they will be transmitted to the host through saliva (Benach et al. 1987, Ribeiro et al. 1987, Zung et al. 1989, Gern et al. 1990). Once infected, this animal will represent an infecting source for other tick individuals. Skin is not only the site of inoculation of the spirochetes but also an important target organ in Iyme borreliosis. In humans, skin is involved in the early and late stages of the disease. Spirochetes have been isolated from the skin of a patient as early as $10 \mathrm{~d}$ after a tick bite (Neubert et al. 1986). Iikewise, in laboratory animals, Lyme borreliosis spirochetes seem to remain at the site of inoculation for $\approx 1$ wk after infecting ticks become engorged and detached (Shih et al. 1992, 1993).

Feeding ticks are generally spatially distributed in clusters on the vertebrate hosts. This clustering may have implications on the transmission of tickborne pathogens. In fact, transmission of pathogens from infected ticks to uninfected ticks through the host skin has been shown previously for intracellular and nonmotile microorganisms. Efficient transmission of Thogoto virus and tick- borne encephalitis virus has been demonstrated from infected ticks to uninfected ticks cofeeding in chambers on nonviremic hosts (Jones et al. 1987, Alekseev and Chunikhin 1990, Labuda et al. 1992). Because spirochetes seem to remain in the inoculation site for a few days after tick detachment, we were interested in testing the effect of tick clustering on the transmission of $B$. burgdorferi and in investigating the hypothesis of a possible cofeeding transmission between infected and uninfected $I$. ricinus ticks.

\section{Materials and Methods}

Ticks, Bacteria, and Mice. Ticks used in this study came from a laboratory colony of spirochetefree $I$. ricinus ticks maintained at the Institut de Zoologie (Neuchâtel) according to the methods described by Graf (1978). The spirochetal isolate of B. burgdorferi (ZS7) used in this study was obtained initially from Ulrich Schaible and Markus Simon (Max-Planck Institut für Immunbiologie, Freiburg, Germany). The spirochetes were grown in modified Barbour-Stoenner-Kelly (BSKII) medium (Barbour 1984). The ZS7 isolate belongs to the $B$. burgdorferi sensu stricto type (Wallich et al. 1992). Female mice of the strains AKR/N and BALB/c were bred at the Institut de Zoologie, Neuchâtel. Animal care and manipulations were in accordance with the Swiss Federal Welfare Laws (LPA and OPA). This study was conducted in accordance with the permit issued by the Cantonal Department of Agriculture. 
Table 1. Infection of $I$. ricinus nymphal ticks fed as larvae on mice together with $B$. burgdorferi-infected nymphs and isolation of spirochetes from mice by culturing ear biopsies

\begin{tabular}{|c|c|c|c|c|c|c|c|}
\hline \multirow[b]{2}{*}{ Mouse no. } & \multirow[b]{2}{*}{ Chamber } & \multicolumn{6}{|c|}{ Day of placement of ticks on mice } \\
\hline & & $\begin{array}{c}\text { Day } 2 \\
\text { No. infected/ } \\
\text { tested }\end{array}$ & $\begin{array}{c}\text { Day } 5 \\
\text { No. infected/ } \\
\text { tested }\end{array}$ & $\begin{array}{c}\text { Day } 8 \\
\text { No. infected/ } \\
\text { tested }\end{array}$ & $\begin{array}{c}\text { Day } 11 \\
\text { No. infected } \\
\text { tested }\end{array}$ & $\begin{array}{c}\text { Day } 14 \\
\text { No. infected } \\
\text { tested }\end{array}$ & $\begin{array}{c}\text { Day } 29 \\
\text { No. infected/ } \\
\text { tested }\end{array}$ \\
\hline 1 & $\begin{array}{l}1 \\
2 \\
\text { head } \\
\text { biopsy }\end{array}$ & $\begin{array}{l}2 / 8 \quad(25) \\
4 / 10(40) \\
0 / 5 \\
\text { Negative }\end{array}$ & $\begin{array}{ll}2 / 9 & (22) \\
2 / 2 & (100) \\
\text { nd } & \\
\text { Negative }\end{array}$ & $\begin{array}{l}\text { No tick } \\
\text { No tick } \\
\text { No tick } \\
\text { Negative }\end{array}$ & $\begin{array}{c}9 / 9 \quad(100) \\
10 / 10(100) \\
0 / 6 \\
\text { Negative }\end{array}$ & $\begin{array}{l}\text { No tick } \\
3 / 3(100) \\
0 / 1 \\
\text { Negative }\end{array}$ & $\begin{array}{l}1 / 5(20) \\
4 / 5(80) \\
4 / 5(80) \\
\text { Positive }\end{array}$ \\
\hline 2 & $\begin{array}{l}1 \\
2 \\
\text { head } \\
\text { biopsy }\end{array}$ & $\begin{array}{l}3 / 11(27) \\
1 / 14(7) \\
\text { No tick } \\
\text { Negative }\end{array}$ & $\begin{array}{l}10 / 13(77) \\
4 / 7 \quad(57) \\
\text { nd } \\
\text { Negative }\end{array}$ & $\begin{array}{l}3 / 4(75) \\
1 / 2(50) \\
\text { No tick } \\
\text { Negative }\end{array}$ & $\begin{array}{cl}4 / 5 & (80) \\
1 / 1 & (100) \\
0 / 9 & \\
\text { Negative }\end{array}$ & $\begin{array}{l}3 / 3(100) \\
\text { No tick } \\
\text { No tick } \\
\text { Negative }\end{array}$ & $\begin{array}{l}\text { nd } \\
\text { nd } \\
\text { nd } \\
\text { nd }\end{array}$ \\
\hline 3 & $\begin{array}{l}1 \\
2 \\
\text { head } \\
\text { biopsy }\end{array}$ & \begin{tabular}{ll}
$5 / 9$ & $(56)$ \\
$3 / 8$ & $(38)$ \\
$0 / 4$ & \\
\multicolumn{2}{l}{ Negative }
\end{tabular} & $\begin{array}{l}6 / 8 \quad(75) \\
4 / 6 \quad(67) \\
0 / 12 \\
\text { Negative }\end{array}$ & $\begin{array}{l}3 / 4(75) \\
\text { No tick } \\
0 / 16 \\
\text { Negative }\end{array}$ & $\begin{array}{l}\text { nd } \\
\text { nd } \\
\text { nd } \\
\text { Negative }\end{array}$ & $\begin{array}{l}\text { nd } \\
\text { nd } \\
\text { nd } \\
\text { nd }\end{array}$ & $\begin{array}{l}\text { nd } \\
\text { nd } \\
\text { nd } \\
\text { nd }\end{array}$ \\
\hline 4 & $\begin{array}{l}1 \\
2 \\
\text { head } \\
\text { biopsy }\end{array}$ & $\begin{array}{l}3 / 7 \quad(43) \\
5 / 13(39) \\
\text { No tick } \\
\text { Negative }\end{array}$ & $\begin{array}{l}0 / 1 \\
\text { No tick } \\
0 / 6 \\
\text { Negative }\end{array}$ & $\begin{array}{l}\text { nd } \\
\text { nd } \\
\text { nd } \\
\text { nd }\end{array}$ & $\begin{array}{l}\text { nd } \\
\text { nd } \\
\text { nd } \\
\text { nd }\end{array}$ & $\begin{array}{l}\text { nd } \\
\text { nd } \\
\text { nd } \\
\text { nd }\end{array}$ & $\begin{array}{l}\text { nd } \\
\text { nd } \\
\text { nd } \\
\text { nd }\end{array}$ \\
\hline
\end{tabular}

Percentage of infected ticks in parentheses. No tick, ticks did not molt; nd, not done.

Infection of Ticks. I. ricinus nymphs that had been infected by capillary feeding (Gern et al. 1990, Hu et al. 1992) with BSKII medium containing $8 \times 10^{7}$ spirochetes per milliliter of strain ZS7 as described previously (Gern et al. 1994) were allowed to feed on uninfected BALB/c mice. One month later, these infected mice were infested with uninfected $I$. ricinus larvae. The derived infected nymphs were used in the cofeeding experiment. The infection rate of the unfed I. ricinus nymphs was $70 \%$ as determined by direct immunofluorescent antibody assay.

Spirochete Detection in Ticks. Ticks were evaluated for $B$. burgdorferi after molting using a direct immunofluorescence antibody test as described previously (Gern et al. 1991). Briefly, ticks were squashed on slides and treated with a fluorescein isothiocyanate-labeled conjugate prepared according to Peacock et al. (1971).

Cofeeding Experiment. Two retaining chambers were glued on the backs of each of 4 uninfected AKR/N mice as described by Mbow et al. (1994). Each chamber was inspected carefully daily and if necessary glue was added. A collar was placed around the neck of each mouse.

To determine whether cofeeding transmission of $B$. burgdorferi can occur between infected and noninfected ticks, 7 infected $I$. ricinus nymphs (infection rate $70 \%$ ) were placed into each chamber on day 0 , and $\approx 20$ uninfected larvae were added into each chamber on days 2 and 5 . To control for the presence of a disseminated infection while infected nymphs were feeding, $\approx 20$ larvae were added freely (that is, not held within chambers) on the head of each mouse on days 2 and 5 and ear biopsies were taken on days 2 and 5, according to Sinsky and Piesman (1989). After detachment of infected nymphs, the localized versus disseminated infection was monitored by adding larvae in the chambers and on the head of the mice and by culturing ear biopsies on days $8,11,14$, and 29 .

Mice were kept in separate cages over trays of water, and engorged ticks that had dropped from the head into the water were collected daily. Chambers were examined daily, and the time of detachment of nymphs and larvae that had fed in the chambers and on the head was noted. Engorged ticks were placed into vials and stored at room temperature and 95\% RH. Ticks were examined for spirochetes after molting using immunofluorescence as described above.

\section{Results}

On day 0 , four $\mathrm{AKR} / \mathrm{N}$ mice were infested with infected I. ricinus nymphs. Engorged infected $I$. ricinus nymphs dropped off on days 5,6 , and 7 after placement into the retaining chambers. From each chamber, 6-7 engorged nymphal ticks were collected. All nymphs fed in the 2 chambers on mice no. 2 ( $n=7$ and 6) and no. $4(n=7$ and 6) dropped off on day 5 , nymphal ticks fed on mouse no. 3 dropped off on day $5(n=6$ and 5$)$ and day $6(n=1$ and 1$)$, and nymphs placed on mouse no. 1 dropped off on day $5(n=5$ and 5), day $6(n=$ 1 ; chamber 1), and day $7(n=1$; chamber 2$)$.

Cofeeding transmission from infected nymphs to uninfected $I$. ricinus larvae was observed for both retaining chambers placed on each of the 4 AKR/N mice ( $=8 / 8$ chambers positive) (Table 1 ). The 1st batch of $I$. ricinus larvae fed in chambers was shown to be infected by B. burgdorferi (infection rate $7-56 \%$ ) for all of the 8 chambers (Table 1). These larvae had been placed on mice on day 2 and fed simultaneously with infected nymphs for at least $3 \mathrm{~d}$. Infection appeared to remain localized 
while cofeeding transmission of $B$. burgdorferi occurred between infected nymphs and uninfected larvae. This was indicated by the fact that culture of ear biopsies taken from all mice on day 2 and on day 5 and examination of a total of 27 larvae collected from the head of 3 of 4 animals on days 2 or 5 , or both, failed to detect $B$. burgdorferi.

After detachment of the infected nymphs, localized infection was observed for 3 of 3 mice by detection of spirochetes in larvae placed in the chambers on day 8 (mouse no. 3); on days 8,11 , and 14 (mouse no. 2); and on days 11, 14, and 29 (mouse no. 1) (Table 1).

The appearance of a disseminated infection was monitored by examining larvae collected from the head of 1 mouse (mouse no. 3) on day 8, 2 mice (mice no. 1 and 2) on day 11, 1 mouse (mouse no. 1) on days 14 and 29 (Table 1). Only the batch of larvae placed on day 29 on mouse 1 was found positive. Ear biopsies taken on days 8 and 11 from mice 1,2 , and 3 remained negative, as well as ear biopsies taken on day 14 from mice 1 and 2 . In contrast, an ear biopsy taken on day 29 from mouse no. 1 was positive.

\section{Discussion}

Tick feeding behavior is characterized by the long duration of the blood meal compared with that of most other hematophagous arthropods. Indeed, Ixodid ticks feed for days to weeks on their hosts before they drop off. Consequently, in natural conditions, a great number of ticks may feed at the same time on the same host. Moreover, ticks are often spatially distributed in clusters on their hosts. This clustering may have some effect on the transmission of tick-borne pathogens, as previously demonstrated with Thogoto and tick-borne encephalitis viruses (Jones et al. 1987, Alekseev and Chunikhin 1990, Labuda et al. 1992). Those studies showed that efficient transmission of these organisms can occur between cofeeding ticks even when the hosts do not develop a detectable viremia.

The vectors of the Lyme borreliosis agent, $B$. burgdorferi, are all ixodid ticks that feed for several days on their hosts. When B. burgdorferi-infected ticks feed on an animal, the spirochetes are injected into the host skin and may remain at the inoculation site for a few days after the end of the blood meal (Shih et al. 1992, 1993). This prompted us to investigate whether cofeeding transmission of a motile and extracellular microorganism like $B$. burgdorferi may occur between infected and uninfected ticks while feeding on a host that had not previously been exposed to the infection.

In our cofeeding experiment, infected $I$. ricinus larvae that had fed simultaneously with infected nymphs in the retaining chambers were collected from all 8 chambers of the $4 \mathrm{AKR} / \mathrm{N}$ mice. This shows that cofeeding transmission of $B$. burgdorferi occurred between infected and noninfected ticks via the host skin in all sites where these ticks were attached. By contrast, no infected larvae were collected from the head of the animals during the same period, demonstrating that infection was localized. These results suggest that infection did not immediately disseminate from the inoculation site. The lack of success in isolating $B$. burgdorferi from ear biopsies collected on days 2 and 5 was consistent with localization of the infection to the skin site in which infected ticks fed. Our results also corroborate previous findings that $B$. burgdorferi remains in the skin near the inoculation site before dissemination (Shih et al. 1992, 1993). Localized infections were observed for the duration of the observation period for each mouse (range, 5-29 d). Evidence of a disseminated infection was shown by the detection of $B$. burgdorferi in an ear biopsy and in 4 of 5 larvae collected from the head of mouse 1 on day 29. Additional studies are needed to determine the time of development of a disseminated infection.

Because $I$. ricinus ticks may be infected by different B. burgdorferi species (Hu et al. 1994), cofeeding transmission of various spirochetes may occur between $I$. ricinus ticks infected by different $B$. burgdorferi species, allowing exchange of spirochetes among ticks, and may partly explain the presence of different $B$. burgdorferi phenotypes/ genotypes in 1 tick, as observed in adult $I$. ricinus ticks (Leuba-Garcia et al. 1994).

Whether $B$. burgdorferi cofeeding transmission can occur between ticks feeding on natural host species remains to be studied. Nevertheless, the demonstration of cofeeding transmission of $B$. burgdorferi has important implications for evaluating the role, in $B$. burgdorferi transmission, of different vertebrate hosts of the tick vector. Most attempts to determine the ability of a particular vertebrate species to support $B$. burgdorferi infection (and to transmit the infection to feeding ticks) have been designed to detect disseminated infection. However by means of cofeeding transmission, it is theoretically possible that tick hosts such as deer may be capable of supporting localized transmission even though they may not develop a disseminated infection.

\section{Acknowledgments}

Special thanks to P. F. Humair for his invaluable help and to Patricia Nuttall for her comments to the manuscript and interesting discussions. We also thank Milan Labuda and Floriane de Marval for discussions, and Markus Simon and Ulrich Schaible for the strain ZS7. This research was financially supported by the Swiss National Science Foundation (No. 32-299964-90), and the Federal Office for Education and Science (No. 93.0363) as part of the European Union Biomedical and Health Research (Biomed I) Programme (No. BMH-CT93-1183).

\section{References Cited}

Alekseev, A. N., and S. P. Chunikhin. 1990. Exchange of tickborne encephalitis virus between Ixod- 
idae simultaneously feeding on the animals with subthreshold levels of viraemia. Med. Parazitol. Parazit. Bolezni. 2: 48-50.

Barbour, A. G. 1984. Isolation and cultivation of Lyme disease spirochetes. Yale J. Biol. Med. 57: 521-525.

Benach, J. L., J. L. Coleman, R. A. Skinner, and E. M. Bosler. 1987. Adult Ixodes dammini in rabbits: a hypothesis for the development and transmission of Borrelia burgdorferi. J. Infect. Dis. 155: 1300-1306.

Gern, L., Z. Zhu, and A. Aeschlimann. 1990. Development of Borrelia burgdorferi in Ixodes ricinus females during blood feeding. Ann. Parasitol. Hum. Comp. 65: 89-93.

Gern, L., L. N. Toutoungi, C. M. Hu, and A. Aeschlimann. 1991. Ixodes (Pholeoixodes) hexagonus, an efficient vector of Borrelia burgdorferi in the laboratory. Med. Vet. Entomol. 5: 431-435.

Gern, L., O. Rais, C. Capiau, P. Hauser, Y. Lobet, E. Simoen, P. Voet, and J. Pêtre. 1994. Immunization of mice by recombinant OspA preparations and protection against Borrelia burgdorferi infection induced by Ixodes ricinus tick bites. Immunol. Lett. 39 : 249-258.

Graf, J. F. 1978. Copulation, nutrition et ponte chez Ixodes ricinus L. (Ixodoidea: Ixodidae), lère partie. Bull. Soc. Entomol. Suisse 51: 89-97.

Hu, C. M., L. Gern, and A. Aeschlimann. 1992. Changes in the protein profiles and antigenicity of different Borrelia burgdorferi strains after reintroduction to Ixodes ricinus ticks. Parasitol. Immunol. 14: 415-427.

Hu, C. M., S. Leuba-Garcia, A. Aeschlimann, M. D. Kramer, and L. Gern. 1994. Comparison in the immunological properties of Borrelia burgdorferi isolates from Ixodes ricinus derived from three endemic areas in Switzerland. Epidemiol. Infect. 112: 533-542.

Jones, L. D., C. R. Davies, G. M. Steele, and P. A. Nuttall. 1987. A novel mode of arbovirus transmission involving non-viraemic host. Science (Washington, DC) 237: 775-777.

Labuda, M., L. D. Jones, T. Williams, V. Danielova, and P. A. Nuttall. 1992. Efficient transmission of tick-borne encephalitis virus between co-feeding ticks. J. Med. Entomol. 30: 295-299.

Leuba-Garcia, S., M. D. Kramer, R. Wallich, and L. Gern. 1994. Characterization of Borrelia burgdor- feri isolated from different organs of Ixodes ricinus ticks collected in nature. Zentralbl. Bakteriol. 280: $468-475$.

Mbow, M. L., M. Christe, B. Rutti, and M. Brossard. 1994. Absence of acquired resistance to nymphal Ixodes ricinus ticks in $\mathrm{BALB} / \mathrm{c}$ mice developing $\mathrm{cu}-$ taneous reactions. J. Parasitol. 80: 81-87.

Neubert, U., H. E. Krampitz, and H. Engl. 1986. Microbiological findings in erythema (chronicum) migrans and related disorders. Zentralbl. Bakteriol. Hyg. Ser. A 263: 237-252.

Peacock, M., W. Burgdorfer, and R. S. Ormsbee. 1971. Rapid fluorescent-antibody conjugation procedure. Infect. Immun. 3: 355-357.

Ribeiro, J.M.C., T. N. Mather, J. Piesman, and A. Spielman. 1987. Dissemination and salivary delivery of Lyme disease spirochetes in vector ticks. J. Med. Entomol. 24: 201-205.

Shih, C. M., R. J. Pollack, S. R. Telford III, and A. Spielman. 1992. Delayed dissemination of Lyme disease spirochetes from the site of deposition in the skin of mice. J. Infect. Dis. 166: 827-831.

Shih, C. M., S. R. Telford III, R. J. Pollack, and A. Spielman. 1993. Rapid dissemination by the agent of Lyme disease in hosts that permit fulminating infection. Infect. Immunol. 61: 2396-2399.

Sinsky, R. J., and J. Piesman. 1989. Ear punch biopsy method for detection and isolation of Borrelia burgdorferi from rodents. J. Clin. Microbiol. 27: 1723-1727.

Wallich, R., S. E. Moter, M. D. Kramer, L. Gern, H. Hofman, U. E. Schaible, and M. M. Simon. 1992. Untersuchungen zur genotypischen and phaenotypischen Heterogenitaet von Borrelia burgdorferi, dem Erreger der Lyme Borreliose, pp. 176-190. In D. Hassler [ed.], Infection Taschenbuch. MMV Medizin, München.

Zung, J. L., S. Lewengrub, M. A. Rudzinska, A. Spielman, S. R. Telford III, and J. Piesman. 1989. Fine structural evidence for the penetration of the Lyme disease spirochete Borrelia burgdorferi through the gut and salivary tissues of Ixodes dammini. Can. J. Zool. 67: 1737-1748.

Received for publication 7 March 1995; accepted 28 July 1995. 